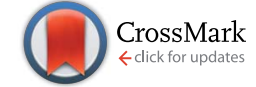

Cite this: RSC Adv., 2017, 7, 13784

Received 28th January 2017

Accepted 23rd February 2017

DOI: $10.1039 / \mathrm{c} 7 \mathrm{ra01226h}$

rsc.li/rsc-advances

\title{
Releasing cation diffusion in self-limited nanocrystalline defective ceria thin films
}

\author{
V. Esposito, ${ }^{* a}$ D. W. Ni, ${ }^{b}$ S. Sanna, ${ }^{a}$ F. Gualandris ${ }^{a}$ and N. Pryds ${ }^{a}$
}

Acceptor-doped nanocrystalline cerium oxide thin films are mechanically constrained nano-domains, with film/substrate interfacial strain and chemical doping deadlock mass diffusion. In contrast, in this paper we show that chemical elements result in highly unstable thin films under chemical reduction, with unexpected diffusion-driven effects such as fast migration of grain boundaries, porosity nucleation, and interdiffusion at low temperatures.

Ceria is a poly-functional material, largely used in energy technologies such as fuel cells, electrolyzers and high temperature thermochemical water splitting. ${ }^{1-6}$ As thin films, ceria compounds have been proposed as key components for miniaturized solid oxide fuel cells and recently in memristors, electrostrictors and in a novel concept of "artificial" ionic conductor. ${ }^{7-12}$ In this respect, mass diffusion effects, i.e. the net flow of mass due to elemental diffusion, play a fundamental role in the materials properties. ${ }^{13-15}$ At the atomic scale, elemental diffusion controls composition, dopants and defect distribution, and segregation. At the microstructural level, mass diffusion controls grain size, porosity, grain boundaries as well as presence of dislocations and voids, therefore affecting the overall mechano-chemo-electrical properties. ${ }^{16,17}$ Due to the strong ionic $\mathrm{Ce}-\mathrm{O}$ bonding at the atomic structure level (enthalpies of formation of $\mathrm{CeO}_{2}, \mathrm{Ce}_{2} \mathrm{O}_{3}$ are 1089, $1796 \mathrm{~kJ}$ $\mathrm{mol}^{-1}$, respectively), ceria-compounds are usually considered stable and highly refractory materials with slow mass flows. ${ }^{18}$ Moreover, acceptor doped ceria, a specific class of important defective ceria compounds, exhibits solute drag effects, where aliovalent and large dopants such as $\mathrm{Sm}^{3+}, \mathrm{Gd}^{3+}, \mathrm{Ca}^{2+}, \mathrm{Y}^{3+}$ can strongly limit the mass flow even at very high temperatures, especially at the grain boundary. ${ }^{19-23}$ Mass diffusion becomes extremely "slow" and/or "self-limited", in highly doped nanocrystalline ceria thin films deposited on dense substrate, e.g. on single crystal or polycrystalline sintered substrates. ${ }^{24}$ As shown by Rupp et al., self-limited effects can severely inhibit diffusive phenomena at the grain boundaries even at temperatures up to $1200{ }^{\circ} \mathrm{C}^{24}$

This is indeed due to the thermo-mechanical expansion of the substrate but also to the combined effect with the chemical solute drag effect in the polycrystalline material. ${ }^{24-26}$

${ }^{a}$ Technical University of Denmark, Department of Energy Conversion and Storage, Frederiksborgvej 399, 4000, Denmark. E-mail: vies@dtu.dk

${ }^{b}$ Shanghai Institute of Ceramics, Chinese Academy of Sciences, Heshuo Road 588\#, Jiading District, Shanghai, China
Although hindered mass diffusion effects in doped ceria are generally dominant, there can be important exceptions. Our recent work showed that above $900{ }^{\circ} \mathrm{C}$ and under low oxygen activity $\left(p_{\mathrm{O}_{2}}<10^{-16}\right.$ atm) doped ceria becomes highly diffusive, with elemental diffusion increasing by several orders of magnitude. For $\mathrm{Ce}_{0.9} \mathrm{Gd}_{0.1} \mathrm{O}_{3-\delta}(\mathrm{CGO})$ at $1400{ }^{\circ} \mathrm{C}$, the mass diffusion coefficient increases from $c a \cdot 10^{-19} \mathrm{~cm}^{2} \mathrm{~s}^{-1}$ at $p_{\mathrm{O}_{2}}=$ $0.21 \mathrm{~atm}$, to $10^{-10} \mathrm{~cm}^{2} \mathrm{~s}^{-1}$ at $p_{\mathrm{O}_{2}}=10^{-12}$ atm..$^{27-32}$ Such a large change brings unexpected effects such as low temperature sintering, fast grain growth, porosity instability, low viscosity and even high reactivity toward other solids. ${ }^{27-32}$ Fast diffusion has indeed important implications in controlling properties and degradation as well as for the material processing.

In this paper, we analyse the "self-limited" case, where highly-doped CGO in the thin film form is constrained, as epitaxial thin film, on a sapphire substrate $\left(\mathrm{Al}_{2} \mathrm{O}_{3}\right.$ single crystal). The latter, also used in Rupp's work, has a large lattice mismatch with ceria that gives the film columnar growth. Moreover, in air sapphire is usually considered highly refractory and chemically inert, especially toward ceria. ${ }^{30,31,33}$

Fig. 1 summarizes the structural and microstructural features of CGO deposition on (1000) $\mathrm{Al}_{2} \mathrm{O}_{3}$ by pulsed laser deposition (PLD). Scanning electronic microscopy (SEM) images in Fig. 1a-e illustrate the typical microstructural features of as-deposited film and for those thermally treated in air. As expected for epitaxial CGO on sapphire (single crystal) substrate, the film exhibited dense polycrystalline microstructure. ${ }^{12,24}$ The as-deposited film showed columnar grains of $c a$. $50 \mathrm{~nm}$ wide and $200 \mathrm{~nm}$ long (Fig. 1a and b) as a result of lattice mismatch between $\mathrm{Al}_{2} \mathrm{O}_{3}$ and CGO lattices. ${ }^{33}$ As a result of the thermal treatments in air, grain growth was observed at $800{ }^{\circ} \mathrm{C}$ (Fig. 1c), $1000{ }^{\circ} \mathrm{C}$ (Fig. 1d) and at $1200{ }^{\circ} \mathrm{C}$ (Fig. 1e). Thermal treatments as long as 15 hours were used to achieve the equilibrium-like configuration in the elemental interdiffusion process. Consistent with the report by Rupp et al., columnar CGO shows limited grain growth below $1000{ }^{\circ} \mathrm{C}$, while grain boundary migration becomes relevant at $1200{ }^{\circ} \mathrm{C}^{24}$ At high 

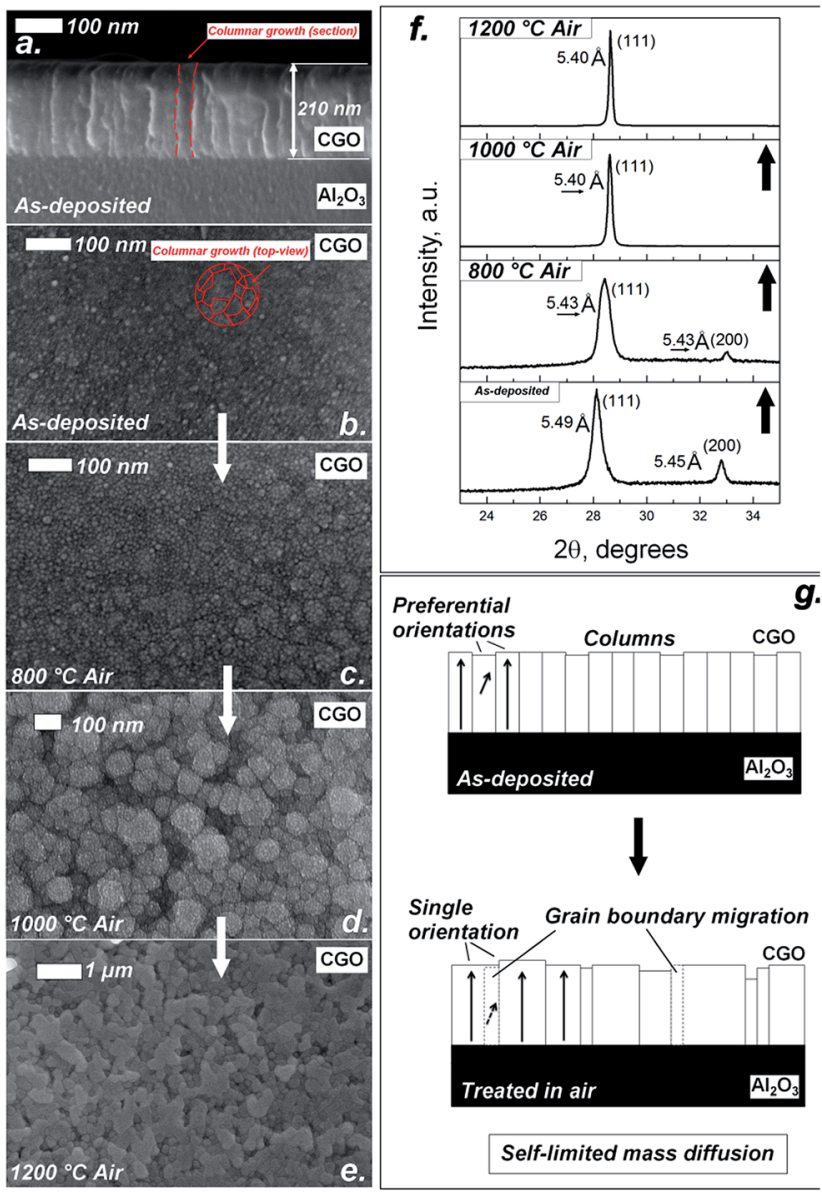

Fig. 1 Panel showing SEM images of typical microstructural features of as-deposited film and for those thermally treated in air for 15 hours: (a) cross section and (b) top view of the as-deposited film on sapphire, (c) top-view after thermal treatment at $800^{\circ} \mathrm{C}$, (d) $1000{ }^{\circ} \mathrm{C}$ and (e) $1200^{\circ} \mathrm{C}$; (f) $\mathrm{XRD}$ characterization of the as-deposited film and after thermal treatment at $800^{\circ} \mathrm{C}, 1000^{\circ} \mathrm{C}$ and $1200^{\circ} \mathrm{C}$ in air for 15 hours; (g) schematic drawing representing the limited mass diffusion for the CGO films treated in air.

temperatures, grain boundary migration occurs by inhomogeneous growth in a limited percentage of grains (ca. $20 \%$ of the grains), which achieve ca. $500 \mathrm{~nm}$ in size (Fig. 1e). Such effect of "abnormal grain growth" is reported here for the first time for highly doped ceria films. The abnormal growth would suggest that in an enhanced mass diffusion regime, columnar formations undergo an Ostwald ripening-like effect (OR). ${ }^{34,35}$ However, due to the columnar-like constrained microstructure, "oriented attachment" (OA) mechanisms are also possible. ${ }^{\mathbf{3 4 , 3 5}}$ In the OA case, adjacent grains self-organize to share a common crystallographic orientation by joining a planar interface, i.e. the grain boundary. Crystal growth via OA mechanisms leads to the formation of crystals with irregular shapes made of "building blocks" of the primary particles. ${ }^{35-37}$ These features can be recognized in Fig. 1e, where larger grains are irregular in shape and are clearly composed of several adjacent smaller grains. The hypothesis of the OA mechanisms is also supported by the fact that the columnar epitaxial films have a preferential orientation. Fig. If especially shows the X-ray diffraction (XRD) patterns corresponding to the different thermal treatment in air. As expected for CGO grown on (1000) $\mathrm{Al}_{2} \mathrm{O}_{3}$, the XRD peaks indicated that the as-deposited film grew with a dominant (111) crystalline arrangement along the out-of-plane direction. Calculation using the (111) peak measured on the $800{ }^{\circ} \mathrm{C}$ sample also indicated a rather stained lattice with a measured lattice constant of $5.49 \AA$ vs. $5.41 \AA$ of the expected bulk CGO ${ }^{33} \mathrm{~A}$ (200)-orientation of the film was also revealed. The additional orientation can be attributed to a rearrangement of the crystal in highly strained conditions. ${ }^{38}$ As reported previously, both strain and multiple orientations in the film can be imposed by the large lattice mismatch, above $16 \%$, between the hexagonal $\mathrm{Al}_{2} \mathrm{O}_{3}$ substrate and fluorite ceria film, which can lead to both elastic and plastic effects on the lattice. ${ }^{11}$ However, XRD characterization in Fig. If shows that the film relaxes, leading to the out-of-plane direction reducing the lattice parameter to $5.43 \AA$ at $800{ }^{\circ} \mathrm{C}$, resulting in complete relaxation after the treatments at $1000{ }^{\circ} \mathrm{C}$ and $1200{ }^{\circ} \mathrm{C}$ for which the lattice parameter has decreased to $5.40 \AA$ A. Interestingly, as a result of the thermal treatments in air, the diffraction at the (200) direction diminished after the treatment at $800{ }^{\circ} \mathrm{C}$ and disappeared at $1000{ }^{\circ} \mathrm{C}$ and $1200{ }^{\circ} \mathrm{C}$. It is worth remarking that, while lattice relaxation can occur without any mass transport, e.g. by structural defect formation and/or annihilation, changes in the film orientation are necessarily linked to a mass flow. The schematic drawing in Fig. $1 \mathrm{~g}$ illustrates the hypothesis that limited mass diffusion in air occurs in the CGO films via grain boundary migration and orientation adjustments. Since mass diffusion in these thin films is self-limited, grain boundary migration occurs between adjacent columns with similar orientations, via OA mechanisms. This in principle requires minor mass transport compared with OR mechanisms, where mass has to be extensively moved from small grains to big ones. ${ }^{34-36}$

For the samples treated in $9 \% \mathrm{H}_{2}-\mathrm{N}_{2}$ a completely different scenario was observed. Fig. 2 shows a similar collection of SEM and $\mathrm{XRD}$ results as shown in Fig. 1. SEM images in Fig. 2a-c show that starting from the same as-deposited thin films and using the same temperatures shown in Fig. 1, low oxygen activity can dramatically affect the microstructure of the CGO film. Fig. 2a shows a clustering of the grains in micron-ranged domains for 15 hours thermal treatment at $800{ }^{\circ} \mathrm{C}$, with formation of intergranular groves. Fast grain growth was also observed at $1000{ }^{\circ} \mathrm{C}$ (Fig. 1b), where the starting columnar dense microstructure is not recognizable, especially due to formation of porous regions and spherical grains. Remarkably, similar morphology was observed by Sanna et al. for $\mathrm{Sm}_{2} \mathrm{O}_{3}$-doped $\mathrm{CeO}_{2}$ as a result of intense oxidation-reduction cycles and electrical measurements at ca. $800{ }^{\circ} \mathrm{C}^{12}$ Such effects are indeed the result of a mass diffusion in the CGO film which allows an extensive reorganization of the materials by flowing of mass. Moreover, these evidences indicated an intrinsic instability of the polycrystalline microstructure under low oxygen activity which was not observed in epitaxial thin films with highly coherent structure, i.e. singlecrystal-like structure with no columnar growth..$^{10,12}$

The effect of mass diffusion on the films is even more dramatic at higher temperatures. Fig. $2 \mathrm{c}$ and d show top-view of the film treated at $1200{ }^{\circ} \mathrm{C}$ and a cold cross section of the film 

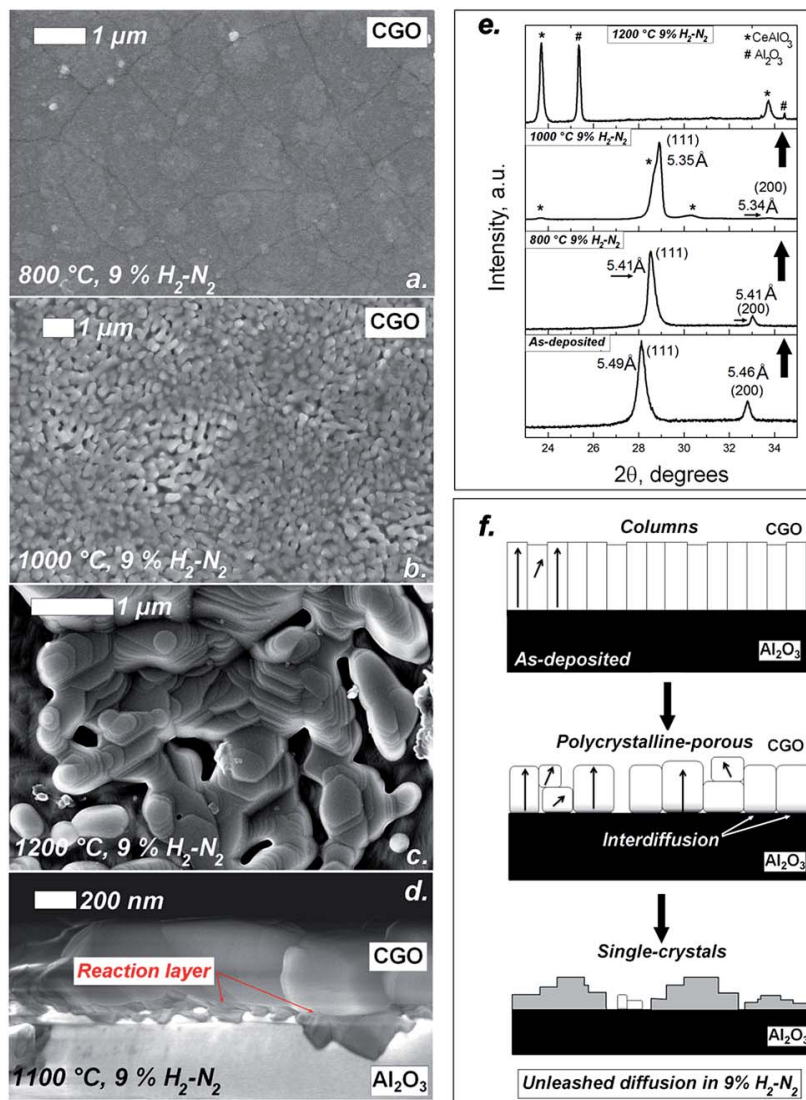

$2 \theta$, degrees

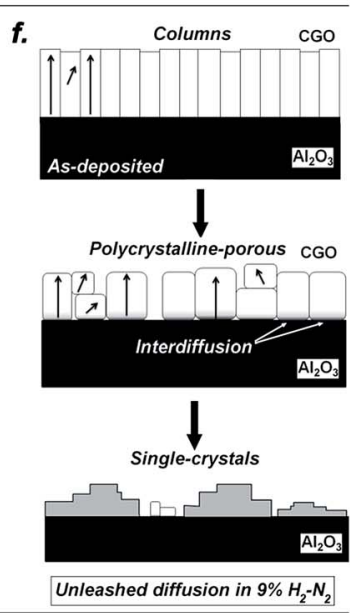

Fig. 2 Panel showing SEM images of typical microstructural features of CGO thin film on sapphire samples thermally treated in $9 \% \mathrm{~N}_{2}-\mathrm{H}_{2}$ for 15 hours: (a) top after thermal treatment at $800^{\circ} \mathrm{C}$, (b) $1000^{\circ} \mathrm{C}$, (c) at $1200{ }^{\circ} \mathrm{C}$ and (d) cross-section of the sample treated at $1100{ }^{\circ} \mathrm{C}$; (e) XRD characterization of the as-deposited and after thermal treatment at $800{ }^{\circ} \mathrm{C}, 1000{ }^{\circ} \mathrm{C}$ and $1200{ }^{\circ} \mathrm{C}$; (f) schematic drawing representing the fast mass diffusion at the CGO films in $9 \% \mathrm{~N}_{2}-\mathrm{H}_{2}$.

treated at $1100{ }^{\circ} \mathrm{C}$ for 15 hours, respectively. After the high temperature treatment the continuous dense films were lost and wide single-crystal-like formations were formed together with large spherical isolated grains (see Fig. 2c). For metal oxides, such formations are generally the result of liquid-like diffusion in the range of above $10^{-10} \mathrm{~cm}^{2} \mathrm{~s}^{-1} \cdot{ }^{16}$ Such a result is indeed unexpected for CGO which has high melting point $\left(>2400{ }^{\circ} \mathrm{C}\right)$ and is self-limited in the nanocrystalline thin film form. Beside the microstructural changes in Fig. 2c, other evidences indicated presence of fast mass diffusion in the film. Particularly, Fig. 2d shows that embedded crystals at the film/ substrate interface formed at $1100{ }^{\circ} \mathrm{C}$. The presence of such crystals clearly indicates the presence of additional phases as a result of solid-solid reaction, i.e. by elemental interdiffusion between $\mathrm{Al}_{2} \mathrm{O}_{3}$ and CGO. Fig. 2e shows the XRD results on the sample after the treatments. Lattice relaxation was already registered at $800{ }^{\circ} \mathrm{C}$, where the lattice contracts from $5.49 \AA$ in the as-deposited film to the bulk value of $5.41 \AA$ after treatment at $800{ }^{\circ} \mathrm{C}$ in $9 \% \mathrm{H}_{2}-\mathrm{N}_{2}$. At temperature as high as $1000{ }^{\circ} \mathrm{C}$ and $1200{ }^{\circ} \mathrm{C}$ we registered clear evidences of degradation in the CGO phase with formation of extra peaks (see markers at the $1000{ }^{\circ} \mathrm{C}$ pattern) and formation of new dominant phases at $1200{ }^{\circ} \mathrm{C}$.
Analysis of the peaks reveals the possible presence of $\mathrm{CeAlO}_{3}$, with dominance of the (110) orientation, and $\mathrm{Al}_{2} \mathrm{O}_{3}$ peaks with different orientation than the sapphire substrate. Similar diffraction pattern and formation of $\mathrm{CeAlO}_{3}$ at low oxygen activity was reported in our previous work. ${ }^{32}$ However, that was the result of elemental interdiffusion at higher temperatures $\left(1450{ }^{\circ} \mathrm{C}\right)$ and low $p_{\mathrm{O}_{2}}$. In this work, clear evidences of $\mathrm{CeAlO}_{3}$ formation are already registered at $1100{ }^{\circ} \mathrm{C}$ where the $p_{\mathrm{O}_{2}}$ is $10^{-22} \mathrm{~atm}$ at $800{ }^{\circ} \mathrm{C}, 10^{-18} \mathrm{~atm}$ at $1000{ }^{\circ} \mathrm{C}$ and $10^{-15} \mathrm{~atm}$ at $1200{ }^{\circ} \mathrm{C}^{27,32}$ In such conditions, large defect concentration is expected in the CGO, with an incipient decomposition of the $\mathrm{CeO}_{2}$ fluorite phase into $\mathrm{Ce}_{2} \mathrm{O}_{3}$ phase. ${ }^{27}$ This change brings chemical expansion, possibly influencing the microstructural evolution during the treatment. Although the kinetics of these drastic changes is difficult to understand by the ex situ characterization, the different steps in the transformations are clearly driven by a large mass flow in the materials. Fig. 2f illustrates a possible model for the microstructural evolution for the CGO thin film at low oxygen activity. This shows that fast mass diffusion occurred leading to microstructural changes, from the dense columnar to porous polycrystalline arrangement, toward new compounds that are formed in a single-crystal fashion.

To confirm such a hypothesis, structural and chemical composition of the phases formed at $1200{ }^{\circ} \mathrm{C}$ were investigated by High Resolution-Transmission Electron Microscope (HRTEM) and Scanning Transmission Electron Microscopy-Energy Dispersive Spectroscopy (STEM-EDS) analysis, respectively. Fig. 3 shows HR-TEM and STEM-EDS line scan elemental
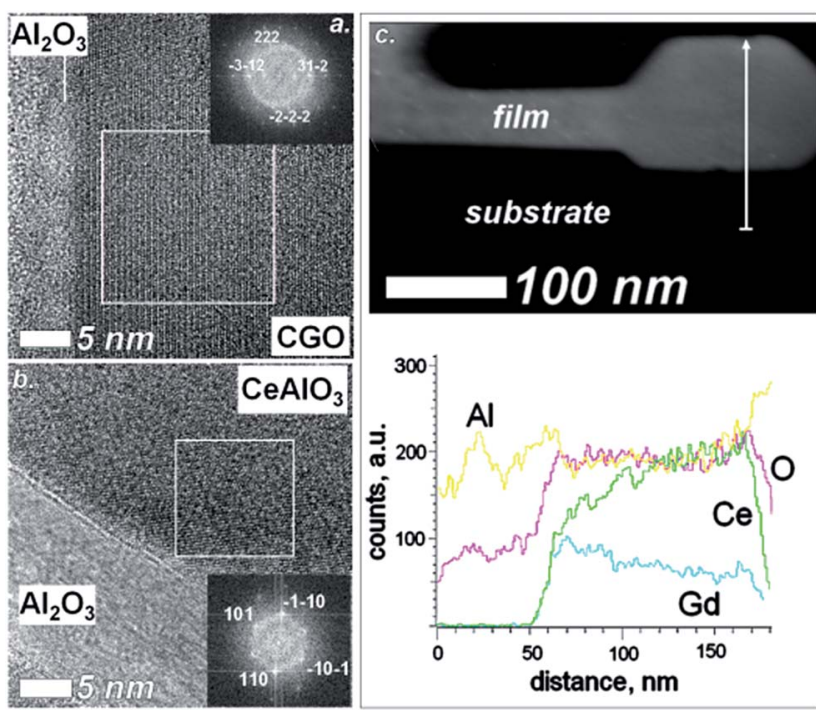

Fig. 3 Panel figure showing (a) HR-TEM image of the interface between $\mathrm{Al}_{2} \mathrm{O}_{3}$ and $\mathrm{CGO}$; the inset represents the FFT from an area (white) at the CGO side of the interface while the bright spots in the FFTs, corresponding to lattice planes visible in the HRTEM image; (b) $\mathrm{HR}-\mathrm{TEM}$ image of the interface between $\mathrm{Al}_{2} \mathrm{O}_{3}$ and the formed $\mathrm{CeAlO}_{3}$; the inset represents the FFT from an area (white) at the CGO side of the interface. It reveals the presence of $\mathrm{CeAlO}_{3}$; (c) STEM-EDS line scan for Al K-alpha, Ce L-alpha, O K-alpha and Gd L-alpha X-ray signal between $\mathrm{Al}_{2} \mathrm{O}_{3}$ and $\mathrm{CGO}$. The upper part of the figure represents a high-angle annular dark-field (HAADF)-STEM image and the arrow indicates the scan path. The nominal beam size was $0.5 \mathrm{~nm}$. 
mapping of the sample at the interfacial region. Fig. 3a shows the presence of residual cubic CGO at the interface with the substrate. The cubic symmetry was revealed by Fast Fourier Transform (FFT) analysis of the white square presented in the image in Fig. 3a (inset Fig. 3a). On the other hand, clear formation of $\mathrm{CeAlO}_{3}$ was found in the sample. Fig. 3b shows an interfacial region at the film/substrate interface in a reacted area. The FFT (insets Fig. 3b) reveals the expected symmetry for the perovskite phase with a typical (110) orientation in the outof-plane direction, as also shown in the inset of Fig. 3b. Presence of $\mathrm{CeAlO}_{3}$ was also confirmed by the elemental analysis which showed a clear intermixing of Ce and Al. Particularly, the absence of both Ce and Gd at the interface (green and blue plots) suggests a preferential diffusion of Al into CGO film (yellow line) rather than a diffusion of ceria into the sapphire. This observation is also consistent with results and thermodynamic calculations we did on this system (results not reported here).

\section{Conclusions}

High oxygen defect concentration in cerium oxide can trigger fast cation diffusion mechanisms, leading to unexpected and dramatic structural and chemical changes in $\mathrm{Ce}_{0.9} \mathrm{Gd}_{0.1} \mathrm{O}_{3-\delta}$. While in high oxygen activity environment, mass diffusion in thin films shows very limited grain boundary migration driven by short-range grain boundary migration, i.e. oriented attachment mechanisms, it results released by the constrained conditions at the same temperatures under low oxygen activity. Some of the effects observed at low oxygen activity are formation of porosity from dense microstructure, abnormal grain growth and even chemical reaction with single crystal sapphire substrate at relatively low temperatures. These findings are thus in contrast with previous literature that showed how highly doped nanocrystalline epitaxial ceria is generally severely constrained by "microstrain and self-limited" effects and give a new insight on chemical and microstructural stability of these thin films under reducing conditions.

\section{References}

1 A. Trovarelli, C. de Leitenburg, M. Boaro and G. Dolcetti, Catal. Today, 1999, 50(2), 353.

2 A. Kaiser, S. P. Foghmoes, G. Pećanac, J. Malzbender, C. Chatzichristodoulou, J. A. Glasscock, D. Ramachandran, V. Esposito, M. Søgaard and P. V. Hendriksen, J. Membr. Sci., 2016, 513, 85.

3 P. Furler, J. R. Scheffe and A. Steinfeld, Energy Environ. Sci., 2012, 5, 6098.

4 B. C. H. Steel and A. Heinzel, Nature, 2001, 414, 345.

5 R. C. Garvie, R. H. Hannink and R. T. Pascoe, Nature, 1975, 258, 70 .

6 C. Walkey, S. Das, S. Seal, J. Erlichman, K. Heckman, L. Ghibelli, E. Traversa, J. F. Mc Ginnis and W. T. Self, Environ. Sci.: Nano, 2015, 2, 33.

7 H.-S. Noh, H. Lee, B.-K. Kima, H.-W. Lee, J.-H. Lee and J.-W. Son, J. Power Sources, 2011, 196, 7169.
8 S. Schweiger, M. Kubicek, F. Messerschmitt, C. Murer and J. L. M. Rupp, ACS Nano, 2014, 8, 5032.

9 R. Korobko, A. Lerner, Y. Li, E. Wachtel, A. I. Frenkel and I. Lubomirsky, Appl. Phys. Lett., 2015, 106, 042904.

10 (a) S. Sanna, V. Esposito, J. W. Andreasen, J. Hjelm, W. Zhang, T. Kasama, S. B. Simonsen, M. Christensen, S. Linderoth and N. Pryds, Nat. Mater., 2015, 14, 500; (b) S. Sanna, V. Esposito, M. Christensen and N. Pryds, APL Mater., 2016, 4, 121101.

11 N. Pryds and V. Esposito, J. Electroceram., 2016, 1-23, DOI: 10.1007/s10832-016-0051-0.

12 (a) K. M. Kant, V. Esposito and N. Pryds, Appl. Phys. Lett., 2012, 100, 033105; (b) K. M. Kant, V. Esposito and N. Pryds, Appl. Phys. Lett., 2010, 97, 143110; (c) S. Sanna, V. Esposito, D. Pergolesi, A. Orsini, A. Tebano, S. Licoccia, G. Balestrino and E. Traversa, Adv. Funct. Mater., 2009, 19(11), 1713.

13 V. Esposito and E. Traversa, J. Am. Ceram. Soc., 2008, 91, 1037.

14 D. W. Ni and V. Esposito, J. Power Sources, 2014, 266, 393.

15 J. Glasscock, V. Esposito, S. P. V. Foghmoes, T. Stegk, D. Matuschek, M. W. H. Ley and S. Ramousse, J. Eur. Ceram. Soc., 2013, 33, 1289.

16 Y.-M. Chiang, D. Birnie III and W. D. Kingery, Physical ceramics, principles for ceramics and engineering, MIT series in material science and engineering, Wiley, New York, 1996, ch. 5 .

17 K. Rodrigo, S. Heiroth, M. Lundberg, N. Bonanos, K. M. Kant, N. Pryds, L. T. Kuhn, V. Esposito, S. Linderoth, J. Schou and T. Lippert, Appl. Phys. A, 2010, 101(4), 601.

18 CRC Handbook of Chemistry and Physics, ed. R. David and R. Lide, CRC, Press, Boca Raton, FL, 86th edn, 2005.

19 P.-L. Chen and I.-W. Chen, J. Am. Ceram. Soc., 1996, 79, 1793. 20 (a) I.-W. Chen, Interface Sci., 2000, 8, 147; (b) P.-L. Chen and I.-W. Chen, J. Am. Ceram. Soc., 1994, 77, 2289.

21 (a) S.-W. Kim, S. G. Kim, J.-I. Jung, S.-J. L. Kang and I. W. Chen, J. Am. Ceram. Soc., 2011, 94, 4231; (b) Y. Dong, H. Wang and I.-W. Chen, J. Am. Ceram. Soc., 2016, 1-9, DOI: $10.1111 /$ jace.14615.

22 D. Z. de Florio, V. Esposito, E. Traversa, R. Muccillo and F. C. Fonseca, J. Therm. Anal. Calorim., 2009, 97, 143.

23 (a) E. Olevsky, T. T. Molla, H. L. Frandsen, R. Bjørk, V. Esposito, D. W. Ni, A. Ilyina and N. Pryds, J. Am. Ceram. Soc., 2013, 96(8), 2657; (b) D. W. Ni, E. Olevsky, V. Esposito, T. T. Molla, S. P. V. Foghmoes, R. Bjørk, H. L. Frandsen, E. Aleksandrova and N. Pryds, J. Am. Ceram. Soc., 2013, 96(8), 2666.

24 J. L. M. Rupp, A. Infortuna and L. J. Gauckler, Acta Mater., 2006, 54(7), 1721.

25 F. Teocoli, D. W. Ni, K. Brodersen, S. P. V. Foghmoes, S. Ramousse and V. Esposito, J. Mater. Sci., 2014, 49, 5324.

26 D. W. Ni, C. G. Schmidt, F. Teocoli, A. Kaiser, K. B. Andersen, S. Ramousse and V. Esposito, J. Eur. Ceram. Soc., 2013, 33, 2529.

27 (a) V. Esposito, D. W. Ni, Z. He, W. Zhang, A. S. Prasad, J. Glasscock, C. Chatzichristodoulou, S. Ramousse and A. Kaiser, Acta Mater., 2013, 61(16), 6290; (b) D. W. Ni, 
D. Z. de Florio, D. Marani, V. B. Tinti and V. Esposito, J. Mater. Chem. A, 2015, 37, 18835.

28 (a) F. Teocoli and V. Esposito, Scr. Mater., 2014, 75, 82; (b) F. Teocoli, D. W. Ni and V. Esposito, Scr. Mater., 2015, 94, 13.

29 D. W. Ni, J. Glasscock, A. Pons, W. Zhang, A. Prasad, S. Sanna, N. Pryds and V. Esposito, J. Electrochem. Soc., 2014, 161(11), F3072.

30 F. Teocoli, D. W. Ni, S. Sanna, K. T. Thydén, F. C. Fonseca and V. Esposito, J. Mater. Chem. A, 2015, 3, 17135.

31 L. Vasylechko, A. Senyshyn, D. Trots, R. Niewa, W. Schnelle and M. Knapp, J. Solid State Chem., 2007, 180, 1277.
32 V. Esposito, D. W. Ni, D. Marani, F. Teocoli, K. T. S. Thydén, D. Z. De Florio and F. C. Fonseca, J. Mater. Chem. A, 2016, 4(43), 16871.

33 T. Skála, N. Tsud, K. C. Prince and V. Matolín, Appl. Surf. Sci., 2011, 257, 3682.

34 A. Baldan, J. Mater. Sci., 2002, 37, 2171.

35 R. L. Penn and J. F. Banfield, Science, 1998, 281, 969.

36 R. L. Penn, J. Phys. Chem. B., 2004, 108, 12707.

37 J. Zhang, F. Huang and Z. Lin, Nanoscale, 2010, 2, 18.

38 S. Sanna, V. Esposito, C. Graves, J. Hjelm, J. W. Andreasen and N. Pryds, Solid State Ionics, 2014, 266, 13. 